\title{
Radiation Synthesis of PVA/ Chitosan Membranes Containing Silver Nanoparticles for Biomedical Applications
}

\author{
A. M. Elbarbary\# and N. M. El-Sawy \\ Radiation Research of Polymer Dept., National Centre for \\ Radiation Research and Technology (NCRRT), P. O. Box; 29 \\ Nasr City, Egypt. ${ }^{\#}$ E-mail; Amelbarbary@yahoo.com.
}

\begin{abstract}
ILVER NANOPARTICLES (AgNPs) were synthesized by $\boldsymbol{\gamma}$-rays of polyvinyl alcohol/ chitosan (PVA/ CS) membranes containing silver nitrate $\left(\mathrm{AgNO}_{3}\right)$ with promising antimicrobial and biomedical applications. The synthesized silver nanoparticles characterized by Ultra Violet spectroscopy (UV), Fourier transform infrared (FT-IR), X-ray diffraction (XRD), and transmission electron microscopy (TEM). UV studies showed a strong peak around $\lambda \max$ at $420 \mathrm{~nm}$. A uniform distribution of silver nanoparticles inside PVA/ CS membranes was achieved by TEM investigation. The prepared silver nanoparticles showed good antimicrobial activity. The membranes containing AgNPs showed non-thrombogenicity effect and slightly haemolytic potential. The prepared membranes containing AgNPs had promising use in biomedical applications.

Keywords: Polyvinyl alcohol/ chitosan, silver nanoparticles, $\gamma$-rays, antimicrobial \& biomedical applications.
\end{abstract}

Synthesis and assembly of nanoparticles or clusters are basic themes in developing science and technology of such specific class of nanomaterials. Metal nanoparticles are attractive due to their easy synthesis, modification as well as their size, shape, distribution which are properties dependent. The metallic nanoparticles, including gold, silver, iron, zinc and metal oxide nanoparticles, have shown great promise in terms of biomedical applications, (Bhattacharya and Mukherjee 2008 and Hussain and Ferguson, 2006).

Silver nanoparticles are of great interest amongst there searchers due to their exquisite properties in nanometer size and to their role as substrates in the studies of catalysis (Shimizu et al., 2010), antibacterial materials (Sowmitri et al., 2006), surface enhancement, surgical devices and wound dressings (Chen and Schluesener 2008), water disinfection (Ruparelia et al., 2008), and in the biomedical field (Rao et al., 2012). 
Many methods have been used for the preparation of silver nanoparticles such as chemical reduction (Lorestani et al., 2015), electrochemical reduction (Hadipour-Goudarzi et al., 2014), photochemical reduction (Kim and Lee 2015), $\gamma$-ray irradiation (Akhavan et al., 2014 and Malkar et al., 2014), UV irradiation (Yang et al., 2014), ultrasonic method (He et al., 2014). Also, different varieties of stabilizers have been used in silver nanoparticles preparation, as mentioned above, to achieve the best control of size, distribution, shape, stability and solubility of silver nanoparticles. The most commonly used stabilizers are polyvinyl pyrrolidone (PVP) and polyethylene glycol (PEG) (Tan et al., 2003), polyvinyl alcohol (PVA) (Abdul-kareem and kaliani 2011). Natural polymers such as starch and chitosan have also been used in the preparation of silver nanoparticles because they are nontoxic and biocompatible (Hettiarachchi and Wickramarachchi 2011). Chitosan is a natural cationic biopolymer consists of Dglucosamine units with excellent bioactivity, biodegradability, and biocompatibility. Chitosan has been reported to be used as stabilizer for silver (Wang et al., 2010), gold (Twu et al., 2008), and metal oxide (Feng et al., 2009) nanoparticles in the chemical reduction and photochemical reduction methods.

$\gamma$-irradiation reduction method has many advantages in the preparation of metal nanomaterials (Li et al., 2007). The hydrated electrons produced during $\gamma$-irradiation can reduce metal ions to metal particles of zero valences (Kumar et al., 2005). This avoids the use of additional reducing agents and the consequent side reactions. Furthermore, the amount of zero-valent nuclei can be controlled by varying the absorbed dose of the irradiation. Homogeneous formation of many nuclei is favourable to result highly dispersed nanoparticles.

In this study, synthesis of PVA/ CS membranes containing silver nanoparticles initiated by $\gamma$-rays will be investigated for possible antimicrobial and biomedical applications.

\section{Materials and methods}

\section{Materials}

CS, DD $85 \%$, Aldrich. PVA, used in this study is a laboratory grade in the form of powder, partially hydrolyzed $(88 \%)$, has an average molecular wt (MW) of 125,000 and was obtained from Laboratory Rasayan, India.

Egypt. J. Rad. Sci. Applic., Vol. 28, No. 1-2 (2015) 
Silver nitrate $\left(\mathrm{AgNO}_{3}\right)$, extra pure, Scharlau, Spain. Glutaraldehyde solution (25 wt\%). Isopropyl alcohol, HPLC grade, Aldrich. Other reagents and solvents were of analytical grade.

\section{Preparation of PVA/CS membranes}

CS solution $(2 \% \mathrm{w} / \mathrm{v})$ was dissolved in dilute acetic acid solution $(1 \% \mathrm{w} / \mathrm{v})$ at room temperature while stirring overnight. The solution was filtered to remove any impurities and/or un-dissolved polymer before use. PVA solution ( $4 \% \mathrm{w} / \mathrm{v})$ was prepared by dissolving PVA in deionized water at $80^{\circ} \mathrm{C}$ with stirring for $4 \mathrm{~h}$. A mixture of CS and PVA solution was stirred at $60^{\circ} \mathrm{C}$ for $2 \mathrm{~h}$ to obtain a homogenous mixture and left overnight with continuous stirring. Synthesis of PVA/ CS membranes were prepared by mixing different compositions of PVA/CS (90/10, 80/20, 70/30, 60/40 and 50/50) with stirring to obtain a homogenous phase and left overnight with continuous stirring. Glutaraldehyde was employed as a crosslinker and added to the resulting polymeric mixture. For this, the required amount of glutaraldehyde $(50 \mathrm{mM}, 1 \mathrm{ml})$ was added slowly to the different mixtures of PVA/ CS solution and was mixed well for $5 \mathrm{~min}$ before casting the resultant solution in the Petri dish. Finally, membranes networks were developed by repeated freezing and thawing cycles for $2 \mathrm{~h}$, respectively.

\section{Radiation synthesis of PVA/CS membranes containing AgNPs}

The same previous mixtures of PVA/ CS were mixed with $\mathrm{AgNO}_{3}$ $(0.1 \mathrm{mM})$ then stirred at $60^{\circ} \mathrm{C}$ for $2 \mathrm{~h}$ to obtain a homogenous phase and left overnight with continuous stirring before casting the resultant solution in the Petri dish. Homogenous membrane was obtained after drying at room temperature for $72 \mathrm{~h}$. Isopropyl alcohol, which is a well-known hydroxyl radical scavenger, was added to the solution which hinders oxidation process of zerovalent silver. Isopropyl alcohol plays an important role in scavenging $\mathrm{OH}$ radicals. In situ reduction of silver ions inside the membrane network was done by $\gamma$-rays at different doses of $15,30,50 \& 70 \mathrm{kGy}$ at dose rate of $2.58 \mathrm{kGy} / \mathrm{h}$.

\section{Characterization Methods}

\section{FT-IR spectroscopy}

The transmittance was measured by infra-red spectrophotometer, JASCO FT-IR 6300, Japan, in the form of $\mathrm{KBr}$ pellets in the range of $400-4000 \mathrm{~cm}^{-1}$.

Egypt. J. Rad. Sci. Applic., Vol. 28, No. 1-2 (2015) 


\section{UV spectroscopy}

The absorbance was measured by UV spectrophotometer JASCO V-560, Japan, in the range from 190 to $600 \mathrm{~nm}$.

\section{$X$-ray diffraction $(X R D)$ studies}

X-ray diffraction patterns were obtained with a XRD-6000 series, Shimadzu apparatus using $\mathrm{Ni}$-filter and $\mathrm{Cu}-\mathrm{K} \alpha$ target.

\section{Particle size studies using Transmission Electron Microscopy (TEM)}

The particle size distribution were studied using a TEM, JEOL JSM-100 CX, Shimadzu Co., Japan, with an acceleration voltage of 80KV. For TEM observations, the samples were prepared by making a suspension from the film in distilled water using ultrasonic water bath. The suspension was centrifuged to separate the polymer matrix and collimate the large size particles. Then a drop of the suspension was put into the carbon grid and left to dry at room temperature.

\section{Surface morphology using Scanning Electron Microscopy (SEM)}

The surface topology of the membranes was measured with SEM, JEOL JSM-5400, Japan, with accelerating voltage of $20 \mathrm{kV}$. The surfaces of membranes were sputter-coated with gold for $3 \mathrm{~min}$.

\section{Antimicrobial activity}

The Antimicrobial activity of PVA/CS membranes with and without silver nanoparticles was evaluated by applying the agar plate diffusion technique were screened in vitro for their anti-bactericidal activity (against Gram positive bacteria Staphylococcus aureus and Gram negative bacteria Escherichia coli) and antifungal activity (against Aspergillas flavus and Candida albicans). For bacterial growth, a lawn of culture was prepared by spreading the $100 \mu \mathrm{L}$ fresh culture having $10^{6}$ colony-forming units (CFU)/ $\mathrm{mL}$ of each test organism on nutrient agar plates with the help of a sterile glass-rod spreader. Plates were left standing for 10min to let the culture get absorbed. In this method, a standard $5 \mathrm{~mm}$ diameter sterilized filter paper disc impregnated with samples was placed on an agar plate seeded with the test organism. The agar plates were then incubated for $24 \mathrm{~h}$ at $37^{\circ} \mathrm{C}$ for bacteria and $28^{\circ} \mathrm{C}$ for fungi. After incubation, the interrupted growth zone (zone of inhibition) around the test material was Egypt. J. Rad. Sci. Applic., Vol. 28, No. 1-2 (2015) 
measured $(\mathrm{mm} / \mathrm{mg})$ and used as quantitative indicator of antibacterial and antifungal effectiveness of silver nanoparticles. The values obtained were the average of 5 measurements on the same plate at different zones. Solvent blank was used as negative control. Antibiotic tetracycline (antibacterial agent) and Amphotericin B (Antifungal agent) were used as positive controls.

\section{Blood compatibility of irradiated PVA/ CS membranes containing AgNPs}

The haemocompatibility was evaluated according to procedure reported in the International Standard Organization (ISO, 1999) and two types of blood interactions were studied i.e. thrombogenicity and haemolytic potential. All studies were carried out in triplicate. The phosphate buffered saline solution (PBS) used for this study was prepared by taking $138 \mathrm{mM} \mathrm{NaCl}, 1.5 \mathrm{mM}$ $\mathrm{KH}_{2} \mathrm{PO}_{4}, 8 \mathrm{mM} \mathrm{Na}_{2} \mathrm{HPO}_{4} \cdot \mathrm{H}_{2} \mathrm{O}$ and $2.7 \mathrm{mM} \mathrm{KCl}$ and $\mathrm{pH}$ was adjusted to $\mathrm{pH}=7.4$ (Lai et al., 2010).

\section{Thrombogenicity}

The evaluation of thrombus formation on polymeric film surface was carried out by a gravimetric method (Imai et al., 1972). Before testing, the films $\left(4 \mathrm{~cm}^{2}\right)$ were kept in PBS for $24 \mathrm{~h}$ at $37^{\circ} \mathrm{C}$. After that PBS was drained out and $2 \mathrm{~mL}$ of acid citrate dextrose (ACD) blood and $0.04 \mathrm{~mL}$ of $0.1 \mathrm{M} \mathrm{CaCl}_{2}$ were placed on the surface of each film (US Pharmacopeia XXIII, 1994). The clotting process was stopped after $45 \mathrm{~min}$ by adding distilled water $(10 \mathrm{ml})$. Clots were fixed by using $36-38 \%$ formaldehyde solution $(5 \mathrm{ml})$. It was filtered, dried and finally weighted. The positive and negative controls were taken as glass beaker without sample and glass beaker without sample and blood (Ferreira et al., 2007). Polyethylene imine was used as positive control whereas, saline used as negative control. The thrombus percentage was calculated as follow:

Thrombose $(\%)=$ Mass of test sample- Mass of (-) control

Mass of (+) control- Mass of (-) control

\section{Haemolytic potential}

The haemolysis tests were performed as described in American Society for Testing and Materials (ASTM) (ASTM F756-00, 2000). Testing film $\left(4 \mathrm{~cm}^{2}\right)$ was kept in $7 \mathrm{ml}$ of PBS taken in polypropylene test tubes. After $24 \mathrm{~h}$ of

Egypt. J. Rad. Sci. Applic., Vol. 28, No. 1-2 (2015) 
incubation at $37^{\circ} \mathrm{C}, 1 \mathrm{ml}$ of diluted ACD blood was added to each sample and kept at $37^{\circ} \mathrm{C}$ for $3 \mathrm{~h}$. Positive and negative controls were prepared by adding the same amount of ACD blood to $7 \mathrm{ml}$ of water and PBS, respectively. Each tube was gently inverted twice to make contact of the blood with the film. After incubation, each fluid was transferred to a suitable tube and centrifuged at $104 \mathrm{rpm}$ for $15 \mathrm{~min}$. The haemoglobin released by haemolysis was measured by the optical densities (OD) of the supernatants at 540nm using UV spectrophotometer. Polyethylene imine was used as positive control whereas saline used as negative control. The percentage of haemolysis was calculated as follows:

$$
\frac{\text { Haemolysis }(\%)=\text { OD of sample }- \text { OD of (-) control }}{\text { OD of }(+) \text { control - OD of (-) control }}
$$

According to ASTM F756-00 materials can be classified in to three different categories according to their haemolysis\% (haemolytic index). Materials with $>5 \%$ haemolysis are classified as haemolytic; while $2-5 \%$ are classified as slightly haemolytic and $<2 \%$ are considered as a non-haemolytic material.

\section{Results and Discussion}

In the present study, due to the importance of silver nanoparticles in antimicrobial and wound dressing applications, silver nanoparticles loaded in PVA/ CS network membranes were in situ reduced by the effect of $\gamma$-rays to form highly dispersed silver nanoparticles. The colour of the membrane of PVA/ CS containing AgNPs changed gradually from yellow to light and deep brown during the irradiation indicating the formation of silver nanoparticles.

\section{Characterization of synthesized PVA/CS membranes containing AgNPs}

\section{FT-IR studies}

FT-IR spectrum of pure PVA membrane (Fig. 1, curve a), shows the absorption peaks at about $3370 \mathrm{~cm}^{-1}$ is due to ${ }^{-} \mathrm{OH}$ stretch vibration. The $\mathrm{C}-\mathrm{H}$ stretching has a strong peak at $2950-2850 \mathrm{~cm}^{-1}$. The bands at $1090 \mathrm{~cm}^{-1}$ and $920 \mathrm{~cm}^{-1}$ are attributed to $\mathrm{C}-\mathrm{O}$ and $\mathrm{C}-\mathrm{C}$ groups, respectively. FT-IR spectrum of CS (Fig. 1,curve b) shows basic characteristic absorption bands at $3440 \mathrm{~cm}^{-1}(\mathrm{O}-$ $\mathrm{H}$ and $\mathrm{N}-\mathrm{H}$ stretch), the band at $1651 \mathrm{~cm}^{-1}$ corresponding to the stretching of Egypt. J. Rad. Sci. Applic., Vol. 28, No. 1-2 (2015) 
$\mathrm{C}=\mathrm{O}$ stretching (amide I $\mathrm{O}=\mathrm{C}-\mathrm{NHR}$ ). The band at $1572 \mathrm{~cm}^{-1}$ is assigned for the $\mathrm{NH}$ bending (amide II) $\left(\mathrm{NH}_{2}\right), 1387 \mathrm{~cm}^{-1}$ (amide), $1154 \mathrm{~cm}^{-1}$ (asymmetric bridgeO-stretch) and $1089 \mathrm{~cm}^{-1}$ (skeletal vibration involving the C-O stretch). FT-IR spectrum of PVA/ CS membrane (Fig. 1, curve c) shows change in the characteristic shape of the CS spectrum as well as hydrogen bonding between$\mathrm{OH}$ of PVA and ${ }^{-} \mathrm{OH}$ or ${ }^{-} \mathrm{NH}_{2}$ of $\mathrm{CS}$ in the blended films. A peak appeared at $3400 \mathrm{~cm}^{-1}$ indicating the presence of hydrogen bonds between chitosan and PVA polymers causing $\mathrm{OH} / \mathrm{NH}_{2}$.

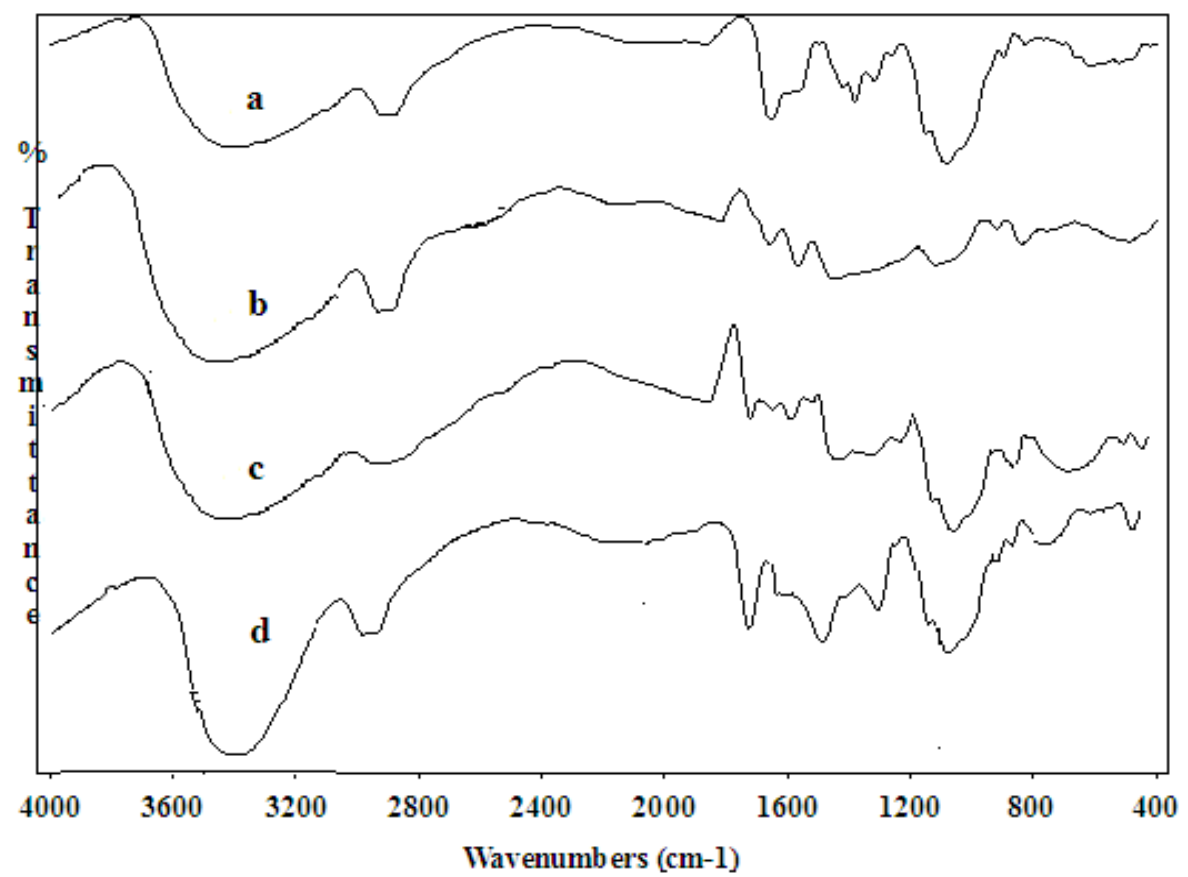

Fig. 1. FT-IR spectra of (a) pure PVA membrane, (b) CS, (c) irradiated PVA/ CS membrane and (d) irradiated PVA/ CS membrane containing AgNPs.

The peaks at 1725,1635 and $1,438 \mathrm{~cm}^{-1}$ may be attributed to carbonyl group stretching, absorption of $\mathrm{NHCOCH}_{3}$ groups and $\mathrm{C}-\mathrm{H}$ bonds present, respectively, in the PVA/ CS polymeric chains. The appearance of carbonyl group in PVA/ CS membrane, even after crosslinking with glutaraldehyde indicates free ${ }^{-} \mathrm{OH}$ moieties of PVA due to the incomplete reaction of glutaraldehyde with hydroxyl groups of PVA (Mansur et al., 2008). In the FTIR spectrum of PVA/ CS containing AgNPs (Fig.1, curve d), a new band Egypt. J. Rad. Sci. Applic., Vol. 28, No. 1-2 (2015) 
appeared at $1723 \mathrm{~cm}^{-1}$, which indicated the attachment of silver to $\mathrm{NH}_{2}$ of $\mathrm{CS}$ and ${ }^{-} \mathrm{OH}$ of PVA. The variation in the shape and peak positions of the $\mathrm{NH}_{2}$ and ${ }^{-} \mathrm{OH}$ at $3450 \mathrm{~cm}^{-1}$ occurred because of contribution toward the reduction and stabilization process. Results showed that the synthesized membranes displayed good compatibility between CS and PVA polymer with significant changes observed after AgNPs incorporation.

\section{UV spectroscopy studies}

Synthesis of silver nanoparticles inside the PVA/ CS membranes at different doses and polymer composition of (70/ 30) was analysed by UV spectroscopy as shown in Fig. 2. A strong peak with a maximum around 412$423 \mathrm{~nm}$ was observed in the UV spectra for irradiated membranes which not present in the non-irradiated membrane because of the fact that AgNPs exhibit an intense absorption peak due to surface Plasmon resonance (SPR) of conducting electrons from the surface of AgNPs. The band absorption increased with increasing the irradiation dose which in agreement with the colour change varies from transparent for the un-irradiated membranes to yellowish brown for the irradiated ones. UV spectrum of PVA/ CS membranes containing AgNPs irradiated at $15 \mathrm{kGy}$ shows broad absorption band at $423 \mathrm{~nm}$. This band is assigned as plasmon resonance band of the small quantity of silver nanoparticles formed at low irradiation dose. The spontaneous formation of AgNPs can be attributed to the direct redox by the effect of irradiation and oxidation of hydroxyl groups of PVA and CS. As the irradiation dose increased from 30-70kGy, the Plasmon band is shifted from 423-415nm and become narrow, sharp and high intensity indicating quantum size effect and so formation of smaller particles. The formation of AgNPs can be attributed to the direct redox of $\mathrm{Ag}^{+}$ions by the effect of irradiation and oxidation of hydroxyl groups of PVA and CS. The particle size is probably related to the amount of the stabilizing polymers chains. The crosslinking of PVA/ CS molecules inhibit the aggregation and/or the growth of the AgNPs. In addition, the increased irradiation dose will increase the nucleation rate which results in formation of smaller particles.

\section{XRD studies}

Fig. 3 shows the XRD pattern of PVA/ CS membrane without $\mathrm{AgNO}_{3}$ irradiated at 50kGy and PVA/ CS membranes containing $\mathrm{AgNO}_{3}$ initiated by $\gamma$ -

Egypt. J. Rad. Sci. Applic., Vol. 28, No. 1-2 (2015) 
rays at different doses of $15,30,50 \& 70 \mathrm{kGy}$ at different doses and polymer composition of (70/ 30). The XRD of PVA/ CS exhibit strong and broad diffraction peak located at $2 \theta=19.66^{\circ}$ corresponding to the (110) reflection as a result of strong intermolecular and intra molecular hydrogen bonding between the PVA molecular chain (Elashmawi et al., 2009). PVA is expected to be noncrystalline but surprisingly it shows distinct crystalline. The high crystalline of PVA is due to the fact that hydroxyl groups are of sufficiently small size to allow the chains to adopt a planar zigzag conformation. PVA/ CS shows highest peak intensity at $2 \theta=19.91^{\circ}$. The XRD of irradiated PVA/ CS containing AgNPs membranes show the corresponding peak of PVA beside four new diffraction at $2 \theta=38.11,44.28,64.61 \& 77.9^{\circ}$ corresponding to (111), (200), (220) \& (311) lattice planes of silver is observed and compared with the standard powder diffraction card of Joint Committee on Powder Diffraction Standards (JCPDS), silver file No. 04-0783. The XRD study confirms that the resultant particles are (FCC) AgNPs corresponding to Face Centre Cubic (FCC).

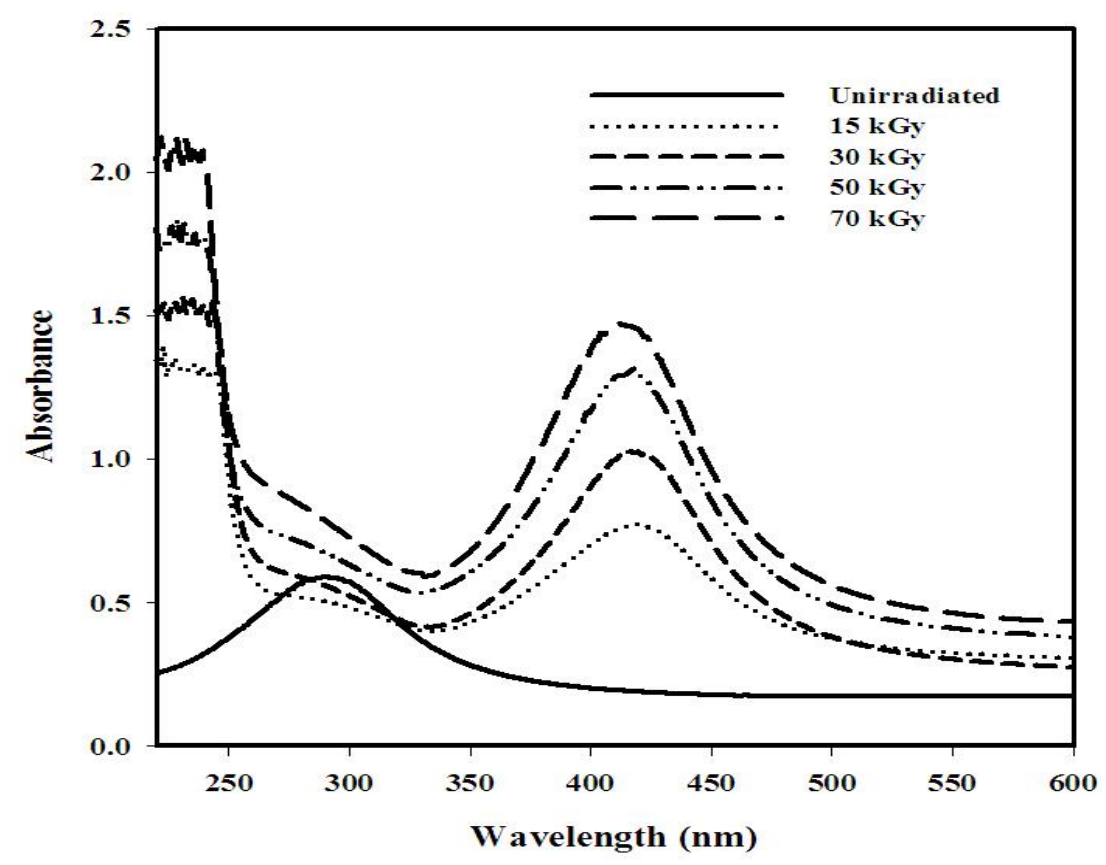

Fig. 2. UV spectra of irradiated and un-irradiated PVA/ CS membrane (copolymer composition 70/30) membranes containing $0.1 \mathrm{mM} \mathrm{AgNO}_{3}$; non-irradiated and irradiated at different doses of $15,30,50 \& 70 \mathrm{kGy}$.

Egypt. J. Rad. Sci. Applic., Vol. 28, No. 1-2 (2015) 


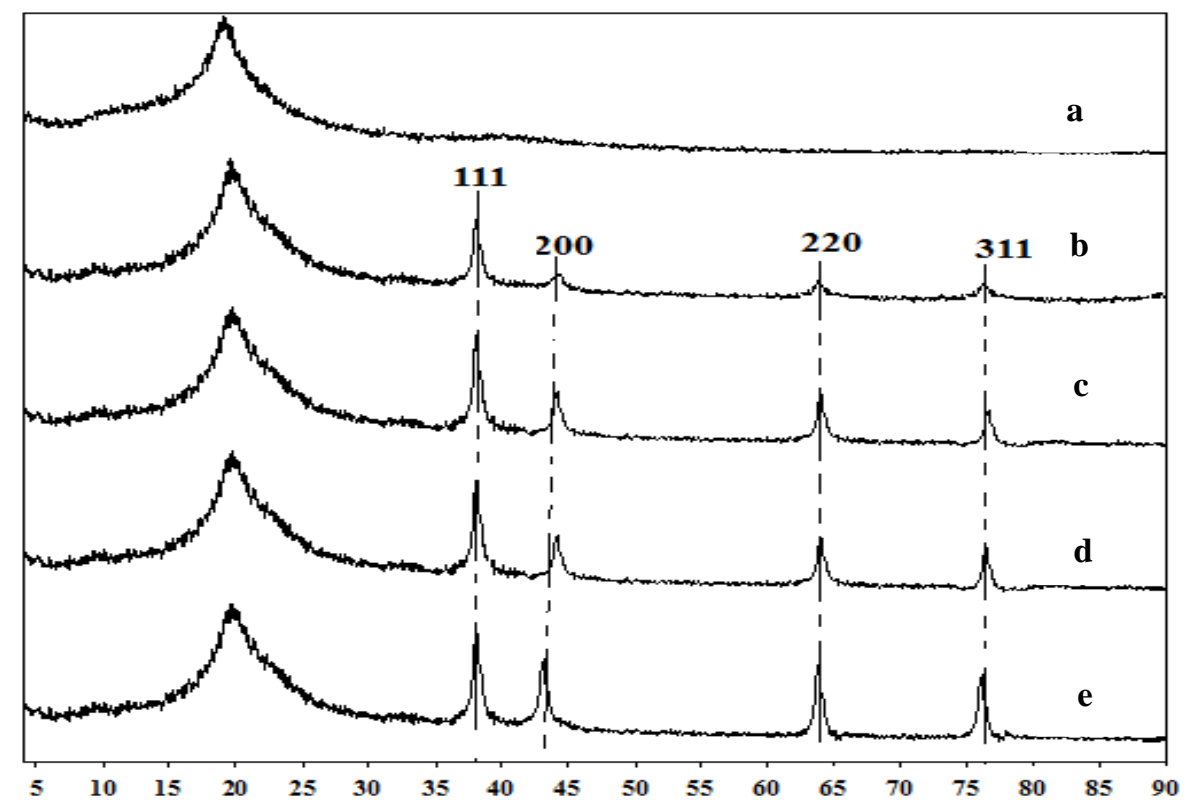

Theata-2theata (deg)

Fig. 3. XRD pattern of (a) $50 \mathrm{kGy}$ irradiated PVA/ CS membrane without $\mathrm{AgNO}_{3}$ and PVA/ CS membrane containing 0.1mM $\mathrm{AgNO}_{3}$ irradiated at (b) 15 $\mathrm{kGy}$, (c) $30 \mathrm{kGy}$, (d) $50 \mathrm{kGy}$ and (e) $70 \mathrm{kGy}$.

\section{Particle size studies using TEM}

Fig. 4. shows uniform distribution of AgNPs inside PVA/ CS membranes could be achieved due to its tendency to form complex and/ or non-covalent interactions with silver ions and the functional moieties present in the PVA/ CS membranes network such as ${ }^{-} \mathrm{OH},{ }^{-} \mathrm{NH}_{2},{ }^{-} \mathrm{C}=\mathrm{O}$ (Bozanic et al., 2010).

Silver ions may get trapped in the free spaces between the crosslinked polymeric networks. Thus, reduction of silver ions using $\gamma$-irradiation results in the formation of silver nanoparticles within as well as in the free spaces between the polymeric chains. The particle size of AgNPs decrese with increasing the irradiation dose. From Fig. 4.

The mean diameter of AgNPs for irradiated PVA/ CS membranes at 15, $30,50 \& 70 \mathrm{kGy}$ was in the range $34,26,19 \& 13 \mathrm{~nm} \pm 3$, respectively.

Egypt. J. Rad. Sci. Applic., Vol. 28, No. 1-2 (2015) 

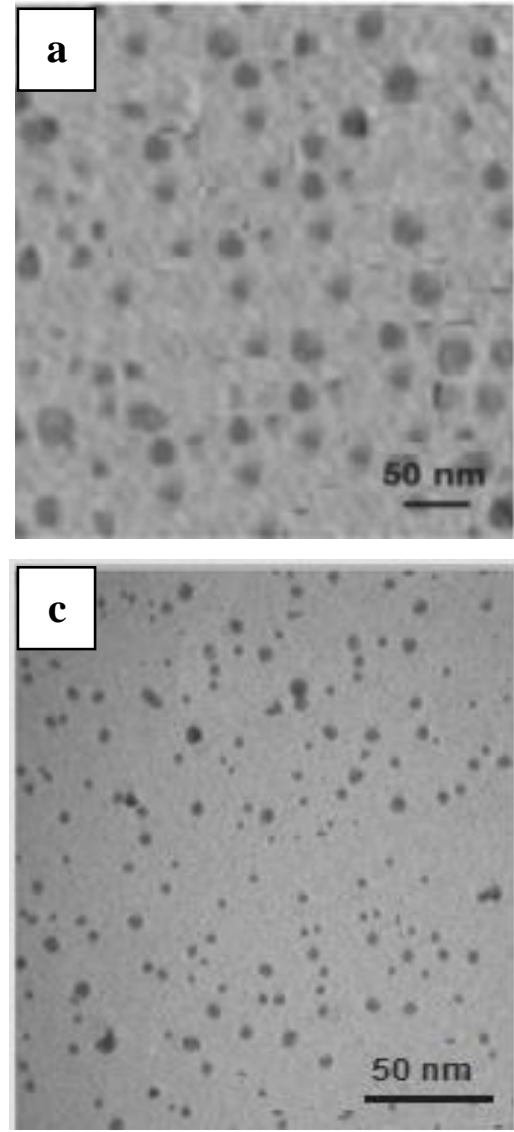
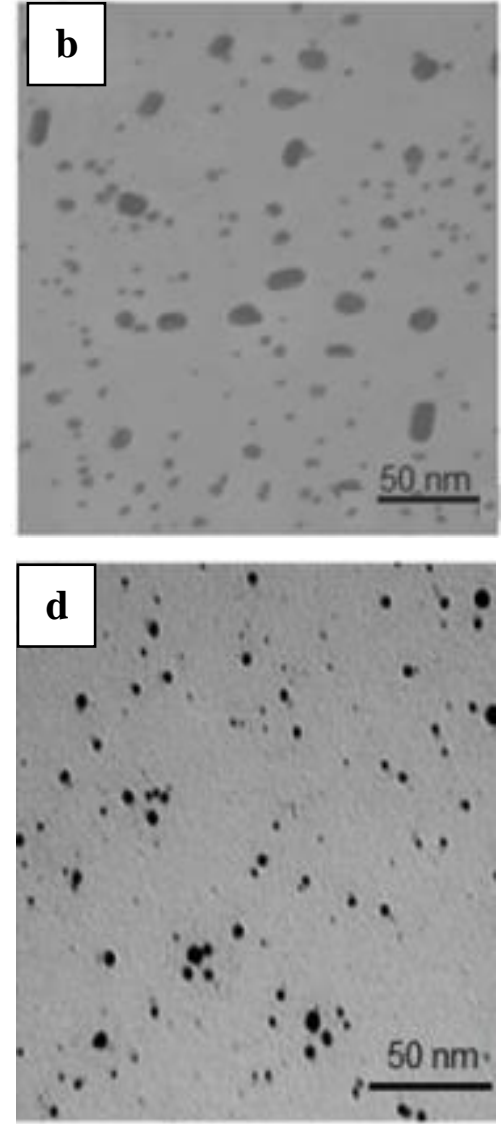

Fig. 4. TEM images for PVA/ CS membrane containing AgNPs (polymer composition of 70/ 30) irradiated at different doses of (a) $15 \mathrm{kGy}$, (b) $30 \mathrm{kGy}$, (c) $50 \mathrm{kGy}$ and (d) $70 \mathrm{kGy}$.

\section{Antimicrobial activity}

Table 1. shows the antibacterial and antifungal activities of irradiated PVA/ CS membrane and irradiated PVA/ CS membranes containing AgNPs as a function of exposure of Gram positive $S$. aureus (bacteria), Gram negative E. coli (bacteria), A. flavus (fungus) and C. albicans as (fungus), which caused a decrease in viable cell counts. The antibacterial effect of silver nanoparticles was more pronounced against Gram-negative (E. coli) than Gram positive (S. aureus). The irradiated PVA/ CS containing AgNPs showed an increase in inhibition zones against $E$. coli and $S$. aureus with increasing the irradiation dose compared to control one or PVA/ CS membranes without Silver. The inhibitory index

Egypt. J. Rad. Sci. Applic., Vol. 28, No. 1-2 (2015) 
against E. coli, S. aureus, A. flavus and C. albicans was 29, 32.1, $23.5 \& 14.3 \%$, respectively for irradiated PVA/ CS membranes without AgNPs compared with the standard materials. The inhibitory index against E. coli, S. aureus, A. flavus and C. albicans for 30kGy irradiated PVA/ CS membranes containing AgNPs was enhanced to $74.1,75,64.7 \& 61.9 \%$, respectively. With increasing the irradiation dose the inhibitory index for membranes containing AgNPs increases. The basis for growth inhibition in pure PVA/CS was due to the inherent antimicrobial nature of the CS polymer present in the membrane network. Polycationic CS can interact with the negatively charged moieties present on the bacterial surface causing membrane leakage, loss in cell permeability and cell death. Therefore, the irradiated membranes containing AgNPs exhibited good antimicrobial activity.

TABLE 1. Antibacterial and antifungal activities of irradiated PVA/ CS membranes with and without AgNPs.

\begin{tabular}{|c|c|c|c|c|c|}
\hline \multirow{2}{*}{\multicolumn{2}{|c|}{ Sample }} & \multicolumn{4}{|c|}{$\begin{array}{c}\text { Inhibition zone diameter } \\
(\mathrm{mm} / \mathrm{mg} \mathrm{sample})\end{array}$} \\
\hline & & $\begin{array}{c}\boldsymbol{E} . \\
\text { Coli } \\
\text { (G ve-) }\end{array}$ & $\begin{array}{c}S . \\
\text { aureus } \\
(\mathrm{G} \mathrm{ve}+)\end{array}$ & $\begin{array}{c}\text { A. } \\
\text { flavus }\end{array}$ & $\begin{array}{c}C . \\
\text { albicans }\end{array}$ \\
\hline \multicolumn{2}{|r|}{ Control } & $\mathbf{0}$ & $\mathbf{0}$ & $\mathbf{0}$ & $\mathbf{0}$ \\
\hline \multirow{2}{*}{ Standard } & Tetracycline (Antibacterial Ag.) & 31 & 28 & - & - \\
\hline & Amphotericin B (Antifungal Ag.) & - & - & 17 & 21 \\
\hline \multicolumn{2}{|r|}{ 50kGy PVA/ CS } & 9 & 9 & 4 & $\mathbf{3}$ \\
\hline \multicolumn{2}{|r|}{ 30kGy PVA/ CS/ AgNPs } & 23 & 21 & 11 & 13 \\
\hline \multicolumn{2}{|r|}{ 50kGy PVA/ CS/ AgNPs } & 25 & 24 & 14 & 14 \\
\hline \multicolumn{2}{|r|}{ 70kGy PVA/ CS/ AgNPs } & 29 & 27 & 15 & 16 \\
\hline
\end{tabular}

\section{Blood compatibility studies}

\section{Thrombogenicity}

Thrombogenicity refers to the tendency of a material in contact with the blood to produce a thrombus or clot. All materials are considered to be thrombogenic. The aggregations of the blood cells on the surface of 50kGy irradiated PVA/ CS membrane without AgNPs and 50kGy irradiated PVA/ CS membrane containing AgNPs was shown in Fig. 5. The results showed aggregation of the blood cells on the surface PVA/ CS membrane while irradiated PVA/ CS membrane containing AgNPs revealed no aggregation of blood cells on

Egypt. J. Rad. Sci. Applic., Vol. 28, No. 1-2 (2015) 
their surface. The initial event when a material comes in contact with blood is the adsorption of proteins. Thrombogenicity of 30kGy irradiated PVA/ CS membranes containing AgNPs and 70kGy irradiated PVA/ CS membranes containing AgNPs were studied and wt of clot and percentage of thrombose formed are shown in Table 2. The results showed that wt of clot formed by the membranes of 30kGy irradiated PVA/ CS containing silver nanoparticles and 70kGy irradiated PVA/ CS containing AgNPs and control test was 0.136, $0.0748 \& 0.385 \mathrm{~g}$, respectively. It was observed that wt of blood clot for irradiated PVA/CS containing AgNPs membranes was less than that of the control which play an important role in reducing the adhesion, aggregation, and activation of blood cells and show good nonthrombogenicity in the clinical use thus the membranes are classified as non-thrombogenic.

\section{Haemolytic potential}

Table 2. shows the results of the haemolytic potential of 30kGy irradiated PVA/ CS membranes containing AgNPs and 70kGy irradiated PVA/ CS membranes containing AgNPs with haemolytic index percentage of 2.359 and $2.1 \%$, respectively. From the results, it is observed that haemolytic percentage was between $2 \%$ and $5 \%$ and it is slightly haemolytic. Hence, these polymeric films can be proposed as biocompatible in nature and may be used in designing wound dressings.
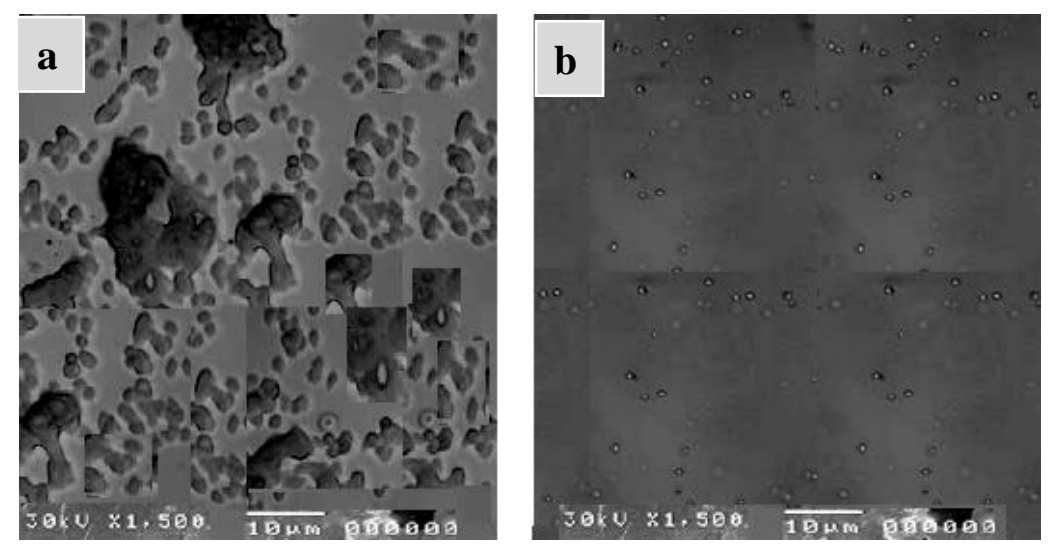

Fig. 5. SEM images for the aggregations of the blood cells on the surface (a) $50 \mathrm{kGy}$ irradiated PVA/ CS membrane without AgNPs and (b) 50kGy irradiated PVA/ CS membrane containing AgNPs.

Egypt. J. Rad. Sci. Applic., Vol. 28, No. 1-2 (2015) 
TABLE 2. Results of blood compatibility studies.

\begin{tabular}{|c|c|c|c|c|c|c|}
\hline \multicolumn{7}{|c|}{ Thrombogenicity } \\
\hline $\begin{array}{c}\text { Polymer } \\
\text { membrane }\end{array}$ & $\begin{array}{c}\text { Wt of } \\
\text { blood clot } \\
(\mathrm{g})+\text { ve } \\
\text { control }\end{array}$ & \begin{tabular}{|c|} 
Wt of \\
blood clot \\
(g) -ve \\
control
\end{tabular} & $\begin{array}{c}\text { Wt of } \\
\text { blood clot } \\
(\mathrm{g})\end{array}$ & \multicolumn{2}{|c|}{$\begin{array}{c}\text { Thromboses } \\
(\%)\end{array}$} & Inference \\
\hline $\begin{array}{c}30 \mathrm{kGy} \\
\text { PVA/ CS/ ÄgNPS }\end{array}$ & 0.385 & 0.0214 & 0.136 & \multicolumn{2}{|c|}{33.51} & $\begin{array}{c}\text { Non- } \\
\text { thrombogenic }\end{array}$ \\
\hline $\begin{array}{c}\text { 70kGy } \\
\text { PVA/ CS/ AgNPS }\end{array}$ & & & 0.0748 & \multicolumn{2}{|c|}{14.7} & $\begin{array}{c}\text { Non- } \\
\text { thrombogenic }\end{array}$ \\
\hline \multicolumn{7}{|c|}{ Haemolytic index } \\
\hline \multicolumn{2}{|c|}{ Polymer membrane } & $\begin{array}{c}\text { OD at } \lambda_{\max }= \\
540 \mathrm{~nm}\end{array}$ & \multicolumn{2}{|c|}{$\begin{array}{c}\text { Haemolytic } \\
\text { Index (H.I.) }(\%)\end{array}$} & \multicolumn{2}{|r|}{ Inference } \\
\hline \multicolumn{2}{|c|}{ 30kGy PVA/ CS/ AgNPS } & 0.272 & \multicolumn{2}{|c|}{2.359} & \multicolumn{2}{|c|}{ Slightly haemolytic } \\
\hline \multicolumn{2}{|c|}{ 70kGy PVA/ CS/ AgNPS } & 0.2426 & \multicolumn{2}{|c|}{2.1} & \multicolumn{2}{|c|}{ Slightly haemolytic } \\
\hline
\end{tabular}

\section{Conclusions}

PVA/ CS membranes containing AgNPs were in situ synthesized by $\gamma$-rays. The characterization analysis UV, XRD and TEM of the prepared membranes showed formation of $\mathrm{Ag}$ in the range of nanoparticles. The antibacterial activity and antifungal activity of AgNPs was tested and the results showed good antimicrobial activity with significant reduction in microbial growth. PVA/ CS membrane containing silver nanoparticles revealed no aggregation of blood cells on their surface. Thrombogenicity and haemolytic potential studies showed that wt of blood clot for PVA/ CS containing AgNPs membranes was less than that of the control thus the membranes are classified as non-thrombogenic and slightly haemolytic suggesting their possible use in biomedical applications.

\section{References}

Abdul-kareem, K. and Kaliani, A. A. (2011) Synthesis and thermal study of octahedral silver nano-plates in polyvinyl alcohol (PVA). Arab J. Chem., 4, 325.

American Society for Testing and Materials, ASTM F756-00, 2000) Standard particles for assessment of haemolytic properties of materials, Philadelphia.

Akhavan, A., Sheikh, N., Khoylou, F., Naimian, F. and Ataeivarjovi, E. (2014)Synthesis of antimicrobial silver/ hydroxyapatite nanocomposite by gamma irradiation. Rad. Phys. Chem., 98, 46.

Bhattacharya, R. and Mukherjee, P. (2008) Biological properties of "naked" metal nanoparticles. Adv. Drug. Deliv. Rev., 60, 1289.

Bozanic, D. K., Trandafilovic, L. V., Luyt, A. S. and Djokovic, V. (2010) Green synthesis and optical properties of silver-chitosan complexes and nanocomposites. React. Funct. Polym., 70, 869.

Egypt. J. Rad. Sci. Applic., Vol. 28, No. 1-2 (2015) 
Chen, X. and Schluesener, H. (2008) Nanosilver: a nanoproduct in medical application. J. Toxicol. Lett., 176, 1.

Elashmawi, I., Hakeem, N. and Selim, M. (2009) Optimization and spectroscopic studies of CdS/ poly (vinyl alcohol) nanocomposites. Mater. Chem. Phys., 115, 132.

Feng, B., Hong, R. Y., Wu, Y. J., Liu, G. H., Zhong, L. H., Zheng, Y., Ding, J. M. and Wei, D. G. (2009) Synthesis of monodisperse magnetite nanoparticles via chitosan-poly(acrylic acid) template and their application in MRI. J. Alloys Compd., 473, 356.

Ferreira, P., Pereira R., Coelho, J. F., Silva, A. F. and Gil, M. (2007) Modification of the biopolymer castor oil with free isocyanate groups to be applied as bioadhesive. Int. J. Biol. Macromol., 40, 144.

Hadipour-Goudarzi E., Montazer, M., Latifi, M. and Aghaji, A. A. G. (2014) Electrospinning of chitosan/ sericin/ PVA nanofibers incorporated with in situ synthesis of nano silver. Carbohyd. Polym., 113, 231.

He, C., Liu, L., Fang, Z., Li, J., Guo, J. and Wei, J. (2014) Formation and characterization of silver nanoparticles in aqueous solution via ultrasonic irradiation. Ultrason. Sonochem., 21, 542.

Hettiarachchi, M. A. and Wickramarachchi, P. A. S. R. (2011) Synthesis of chitosan stabilized silver nanoparticles using gamma ray irradiation and characterization. J. Sci. Univ. Kelaniya Sri Lanka, 6, 65.

Hussain, S. and Ferguson, C. (2006) Silversulphadiazine cream in burns.Emerg. Med. J., 23, 929.

Imai, Y. and Nose, Y. (1972) A new method for evalution of antithrombogenicity of materials. J. Biomed. Mater. Res., 6, 165.

International Standard Organization, ISO 10993-4 (1999) Biological evaluation of medical devices-part 4-selection of tests for interaction with blood, Geneva.

Kim, B. H. and Lee, J. S. (2015) One-pot photochemical synthesis of silver nanodisks using a conventional metal-halide lamp. Mater. Chem. Phys., 149, 678.

Kumar, M., Varshney, L. and Francis, S. (2005) Radiolytic formation of Ag clusters in aqueous polyvinyl alcohol solution and hydrogel matrix. Rad. Phys. Chem., 73, 21.

Lai, Y., Yin, W., Liu, J., Xi, R. and Zhan, J. (2010) One-pot green synthesis and bioapplication of L-arginine capped superparamagnetic $\mathrm{Fe}_{3} \mathrm{O}_{4}$ nanoparticles. Nanoscale Res. Lett., 5, 302.

Li, T., Park, H. G. and Choi, S. H. (2007) $\gamma$-Irradiation-induced preparation of Ag and Au nanoparticles and their characterizations. Mater. Chem. Phys., 105, 325.

Lorestani, F., Shahnavaz, Z., Mn, P., Alias, Y. and Manan N. S. A. (2015) One-step hydrothermal green synthesis of silver nanoparticle-carbon nanotube reduced-graphene oxide composite and its application as hydrogen peroxide sensor. Sens. Actuators B: Chem., 208, 389.

Egypt. J. Rad. Sci. Applic., Vol. 28, No. 1-2 (2015) 
Malkar, V. V., Mukherjee, T. and Kapoor, S. (2014) Synthesis of silver nanoparticles in aqueous aminopolycarboxylic acid solutions via $\gamma$-irradiation and hydrogen reduction. Mater. Sci. Eng. C., 44, 87.

Mansur, H., Sadahira, C, Souza, A. and Mansur, A. (2008) FTIR spectroscopy characterization of poly(vinyl alcohol) hydrogel with different hydrolysis degree and chemically crosslinked with glutaraldehyde. Mater. Sci Eng. C, 28, 539.

Rao, K. S. V. K., Reddy P. R., Lee, Y. I. and Kim, C. (2012) Gamma irradiation route to synthesis of highly re-dispersible natural polymer capped silver nanoparticles. Carbohyd. Polym., 87, 920.

Ruparelia, J. P., Duttagupta, S. P., Chatterjee, A. K. and Mukherji, S. (2008) Strain specificity in antimicrobial activity of silver and copper nanoparticle. Acta Biomater., 4, 707.

Shimizu, K., Miyamoto, Y. and Satsuma, A. (2010) Silica-supported silver nanoparticles with surface oxygen species as a reusable catalyst for alkylation of arenes. Chem. Cat. Chem., $2,84$.

Tan, Y., Dai, X., Li, Y. and Zhu, D. (2003) Preparation of gold, platinum, palladium and silver nanoparticles by the reduction of their salts with a weak reductantpotassium bitartrate. J. Mater. Chem., 13, 1069.

Tarimala, S., Kothari, N., Abidi, N., Hequet, E., Fralic, J. and Dai, L. L. (2006) New approach to antibacterial treatment of cotton fabric with silver nanoparticledoped silica using sol-gel process. J. Appl. Polym. Sci., 101, 2938.

Twu, Y. K., Chen, Y. W. and Shih, C. M. (2008) Preparation of silver nanoparticles using chitosan suspensions. Powder Technol., 185, 251.

US Pharmacopeia XXIII (1994) US Pharmacopeial Convention, Rockville, MD, p. 119.

Wang, B., Zhuang, X., Deng, W. and Cheng, B. (2010) Microwave-assisted synthesis of silver nanoparticles in alkalic carboxymethyl chitosan solution. Eng., 2, 387.

Yang, Z., Zhai, D., Wang, X. and Wei, J. (2014) In situ synthesis of highly mono dispersed on aqueous small-sized silver nano-colloids and silver/ polymer nanocomposites by ultraviolet photopolymerization Colloid. Surf. A: Physicochem. Eng. Aspects., 448, 107.

(Received: 02/08/2015;

accepted: 08/11/2015)

Egypt. J. Rad. Sci. Applic., Vol. 28, No. 1-2 (2015) 


\title{
التحضير الإثعاعي لأغثية البولي القينيل الكحولي/ الكيتوزان

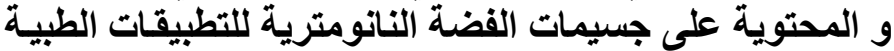 الحيوية
}

أحمد محمد البربزي ، و نعيم محمد الصاوي قسم البحوث الإشعاعية لكيمياء البوليمر ات ، المركز القومي لبحوث و و تكنولوجيا

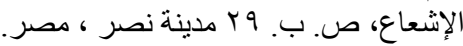

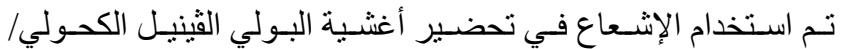

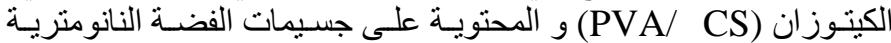

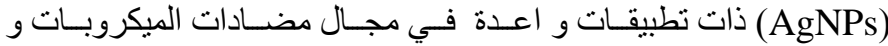

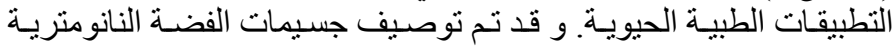

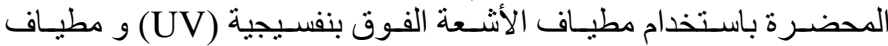

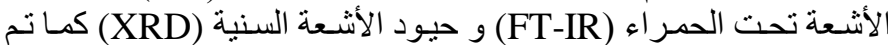
تعيين حجم الجسيمات باستخدام الميكروسكوب الالكتروني النفاذ (TEM).

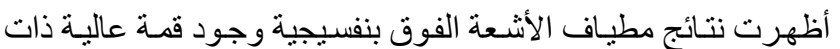

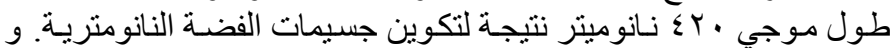

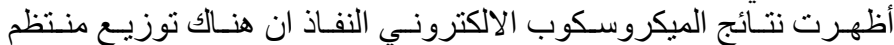

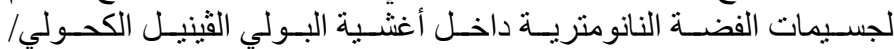

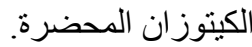

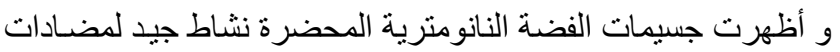

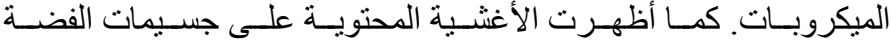

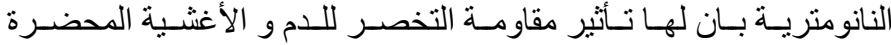
استخدامات واعدة في التطبيقات الطبية الحيوية.
\end{abstract}

Egypt. J. Rad. Sci. Applic., Vol. 28, No. 1-2 (2015) 